This PDF is a selection from an out-of-print volume from the National Bureau of Economic Research

Volume Title: The Demand for Money: Some Theoretical and Empirical Results

Volume Author/Editor: Milton Friedman

Volume Publisher: NBER

Volume ISBN: 0-87014-382-4

Volume URL: http://www.nber.org/books/frie59-1

Publication Date: 1959

Chapter Title: The Demand for Money: Some Theoretical and Empirical Results

Chapter Author: Milton Friedman

Chapter URL: http://www.nber.org/chapters/c5857

Chapter pages in book: (p. 1 - 29) 


\title{
The Demand for Money: Some Theoretical and Empirical Results
}

\author{
MILTON FRIEDMAN
}

OCCASIONAL PAPER 68

NATIONAL BUREAU OF ECONOMIC RESEARCH, INC. 1959

Distributed by Columbia University Press: New York and London 
Reprinted from the August 1959 issue of the Journal of Political Economy

University of Chicago, Economics Department

Library of Congress Catalog Card Number: 59-12559

Price: $\$ 1.50$

NATIONAL BUREAU OF ECONOMIC RESEARCH, Inc. 261 Madison Avenue, New York 16, N.Y. 


\title{
NATIONAL BUREAU OF ECONOMIC RESEARCH
}

\section{9}

\author{
OFFICERS
}

George B. Roberts, Chairman

Arthur F. Burns, President

Theodore W. Schultz, Vice-President

Murray Shields, Treasurer

Solomon Fabricant, Director of Research

Geoffrey H. Moore, Associate Director of Research

William J. Carson, Executive Director

\section{DIRECTORS AT LARGE}

Wallace J. Campbell, Director, Cooperative League of the USA

Solomon Fabricant, New York Universily

Gabriel Hauge, Chairman, Finance Committee, Manufacturers Trust Company

Albert J. Hettinger, Jr., Lazard Frères and Company

Oswald W. Knauth, Beaufort, South Carolina

H. W. Laidler, Executive Director Emeritus, League for Industrial Democracy Shepard Morgan, Norfolk, Connecticut

George B. Roberts, Larchmont, New York Beardsley Ruml, New York City

Harry Scherman, Chairman, Book-of-the-Month Club

Boris Shishkin, American Federation of Labor and

Congress of Industrial Organizations

George Soule, Professor Emeritus, Bennington College

N. I. Stone, Consulting Economist

J. Raymond Walsh, New York Cily

Joseph H. Willits, Director, The Educational Survey, University of Pennsylvania Leo Wolman, Columbia University

Donald B. Woodward, Vick Chemical Company

Theodore O. Yntema, Vice-President-Finance, Ford Motor Company.

V. W. Bladen, Toronto

Arthur F. Burns, Columbia

Melvin G. de Chazeau, Cornell

Frank W. Fetter, Northwestern

H. M. Groves, Wisconsin

Gottfried Haberler, Harvard
DIRECTORS BY UNIVERSITY APPOINTMENT

Walter W. Heller, Minnesota

Maurice W. Lee, North Carolina

Lloyd G. Reynolds, Yale

T. W. Schultz, Chicago

Jacob Viner, Princeton

Willis J. Winn, Pennsylvania

DIRECTORS APPOINTED BY OTHER ORGANIZATIONS

Percival F. Brundage, American Institute of Certified Public Accountants Harold G. Halcrow, American Farm Economic Association Theodore V. Houser, Committee for Economic Development Stanley H. Ruttenberg, American Federation of Labor and Congress of Indusirial Organizations

Murray Shields, American Management Association

Willard L. Thorp, American Economic Association

W. Allen Wallis, American Statistical Association

Harold F. Williamson, Economic History Association

Moses Abramovitz

Gary S. Becker

Gerhard Bry

Arthur F. Burns

Morris A. Copeland

Frank G. Dickinson

James S. Earley

Richard A. Easterlin

Solomon Fabricant

Milton Friedman
RESEARCH STAFF

Raymond W. Goldsmith

Leo Grebler

Millard Hastay

W. Braddock Hickman

Daniel M. Holland

Thor Hultgren

C. Harry Kahn

John W. Kendrick

Simon Kuznets

Clarence D. Long
Ruth P. Mack

Ilse Mintz

Geoffrey H. Moore

Roger R. Murray

G. Warren Nutter

Lawrence H. Seltzer

Robert P. Shay

George J. Stigler

Leo Wolman

Herbert B. Woolley 


\section{Rei.ATION OF THE DiRECTORS}

\section{to the Work and Publications \\ of the National Bureau of Economic Research}

1. The object of the National Bureau of Economic Research is to ascertain and to present to the public important economic facts and their interpretation in a scientific and impartial manner. The Board of Directors is charged with the responsibility of ensuring that the work of the National Bureau is carried on in strict conformity with this object.

2. To this end the Board of Directors shall appoint one or more Directors of Research.

3. The Director or Directors of Research shall submit to the members of the Board, or to its Executive Committee, for their formal adoption, all specific proposals concerning researches to be instituted.

4. No report shall be published until the Director or Directors of Research shall have submitted to the Board a summary drawing attention to the character of the data and their utilization in the report, the nature and treatment of the problems involved, the main conclusions, and such other information as in their opinion would serve to determine the suitability of the report for publication in accordance with the principles of the National Bureau.

5. A copy of any manuscript proposed for publication shall also be submitted to each member of the Board. For each manuscript to be so submitted a special committee shall be appointed by the President, or at his designation by the Executive Director, consisting of three Directors selected as nearly as may be one from each general division of the Board. The names of the special manuscript committee shall be stated to each Director when the summary and report described in paragraph (4) are sent to him. It shall be the duty of each member of the committee to read the manuscript. If each member of the special committee signifies his approval within thirty days, the manuscript may be published. If each member of the special committee has not signified his approval within thirty days of the transmittal of the report and manuscript, the Director of Research shall then notify each member of the Board, requesting approval or disapproval of publication, and thirty additional days shall be granted for this purpose. The manuscript shall then not be published unless at least a majority of the entire Board and a two-thirds majority of those members of the Board who shall have voted on the proposal within the time fixed for the receipt of votes on the publication proposed shall have approved.

6. No manuscript may be published, though approved by each member of the special committee, until forty-five days have elapsed from the transmittal of the summary and report. The interval is allowed for the receipt of any memorandum of dissent or reservation, together with a brief statement of his reasons, that any member may wish to express; and such memorandum of dissent or reservation shall be published with the manuscript if he so desires. Publication does not, however, imply that each member of the Board has read the manuscript, or that either members of the Board in general, or of the special committee, have passed upon its validity in every detail.

7. A copy of this resolution shall, unless otherwise determined by the Board, be printed in each copy of every National Bureau book.

(Resolution adopted October 25, 1926

and revised February 6, 1933 and Febriary 24, 1941) 


\title{
THE DEMAND FOR MONEY: SOME THEORETICAL
}

\section{AND EMPIRICAL RESULTS ${ }^{1}$}

\author{
MIITON FRIEDMAN \\ University of Chicago and National Bureau of Economic Research
}

I COUNTRIES experiencing a secular rise in real income per capita, the stock of money generally rises over long periods at a decidedly higher rate than does money income. Income velocity - the ratio of money income to the stock of money-therefore declines secularly as real income rises. During cycles, to judge from the United States, the only country for which a detailed analysis has been made, the stock of money generally rises during expansions at a lower rate than money income and either continues to rise during contractions or falls at a decidedly lower rate than money income.

\footnotetext{
${ }^{1}$ This paper reports on part of a broader study being conducted at the National Bureau of Economic Research by Anna J. Schwartz and myself. I am indebted to Mrs. Schwartz for extensive assistance and numerous suggestions in connection with the present paper.

This paper has been approved for publication as a report of the National Bureau of Economic Research by the Director of Research and the Board of Directors of the National Bureau, in accordance with the resolution of the board governing National Bureau reports (see the Annual Report of the $\mathrm{Na}$ tional Bureau of Economic Research). It is reprinted as No. 68 in the National Bureau's series of Occasional Papers.
}

Income velocity therefore rises during cyclical expansions as real income rises and falls during cyclical contractions as real income falls-precisely the reverse of the secular relation between income and velocity.

These key facts about the secular and cyclical behavior of income velocity have been documented in a number of studies. ${ }^{2}$ For the United States, Anna Schwartz and $I$ have been able to document them more fully than has hitherto been possible, thanks to a new series on the stock of money that we have constructed which gives estimates at annual or semiannual dates from 1867 to 1907 and monthly thereafter. This fuller documentation does not, however, dispel the apparent contradiction between the secular and the cyclical behavior of income velocity. On the contrary, as the summary

2 See in particular Richard T. Selden, "Monetary Velocity in the United States," in Milton Friedman (ed.), Studies in the Quantity Theory of Money (Chicago: University of Chicago Press, 1956), pp. 179257; and Ernest Doblin, "The Ratio of Income to Money Supply: An International Survey," Review of Economics and Statistics, August, 1951, p. 201. 
of our findings in the following section makes explicit, it reveals an additional contradiction or, rather, another aspect of the central contradiction.

Previous attempts to reconcile the secular and cyclical behavior of the velocity of circulation of money have concentrated on variables other than income, such as the rate of interest or the rate of change of prices. These attempts have been unsuccessful. While such other variables doubtless affect the quantity of money demanded and hence the velocity of circulation of money, most do not have a cyclical pattern that could explain the observed discrepancy. In any event, it seems dubious that their influence on velocity is sufficiently great to explain so large a discrepancy.

An alternative theoretical explanation of the discrepancy is suggested by the work I have done on consumption-a rather striking example of how work in one field can have important implications for work in another that has generally been regarded as only rather distantly related. This theoretical explanation, which concentrates on the meaning attached to "income" and to "prices," is presented in Sections II and III below and turns out to be susceptible of quantitative test. The quantitative evidence in Section IV is highly favorable. The result is both a fuller understanding of the observed behavior of velocity and a different emphasis in the theory of the demand for money.

One important feature of monetary behavior not accounted for by this explanation is the consistent tendency for actual cash balances, adjusted for trend, to lead at both peaks and troughs in general business. In Section V, a preliminary attempt is made to explore factors that might account for the discrepancy between desired cash balances as determined by income alone and actual cash balances. Finally, in Section VI, some broader implications of the results presented in this paper are explored.

\section{A SUMMARY OF THE EMPIRICAL EVI- DENCE FOR THE UNITED STATES}

A full documentation of our findings about the secular and cyclical behavior of the stock of money and its relation to income and prices will be given in a nearly completed National Bureau of Economic Research monograph by Anna J. Schwartz and myself. For present purposes, a brief summary of a few of our findings will suffice.

\section{A. SECULAR BEHAVIOR}

1. Secular changes in the real stock of money per capita are highly correlated with secular changes in real income per capita. In order to study this relation, we have used average values over complete reference cycles as our elementary observations. For twenty cycles measured from trough to trough and covering the period from 1870 to 1954 , the simple correlation between the logarithm of the real stock of money per capita and the logarithm of real income per capita is 0.99 , and the computed elasticity is $1.8 .^{3}$

A 1 per cent increase in real income per capita has therefore, on the average, been associated with a 1.8 per cent increase in real cash balances per capita and hence

\footnotetext{
${ }^{3}$ The corresponding figures for cycles measured from peak to peak are 0.99 and 1.7. In these and later correlations, "money" is defined as including currency held by the public, adjusted demand deposits, and time deposits in commercial banks. This total is available for the period from 1867 on, whereas the total exclusive of time deposits is not available until 1914. For other reasons supporting our definition see the NBER monograph now in preparation. For income, we have used Simon Kuznets' estimates of net national product adjusted for wartime periods to a concept approximating that underlying the current Department of Commerce estimates, and for prices, the deflator implicit in Kuznets' estimates of net national product in constant prices.
} 
with a 0.8 per cent decrease in income velocity. If we interpret these results as reflecting movements along a stable demand relation, they imply that money is a "luxury" in the terminology of consumption theory. Because of the strong trend element in the two series correlated, the high correlation alone does not justify much confidence that the statistical regression is a valid estimate of a demand relation rather than the result of an accidental difference in trends. However, additional evidence from other sources leads us to believe that it can be so regarded.

We have investigated the influence of both rates of interest and rates of change of prices. In our experiments, the rate of interest had an effect in the direction to be expected from theoretical considerations but too small to be statistically significant. We have not as yet been able to isolate by correlation techniques any effect of the rate of change of prices, though a historical analysis persuades us that such an effect is present.

2. Over the nine decades that we have studied, there have been a number of long swings in money income. As a matter of arithmetic, these swings in money income can be attributed to movements in the nominal stock of money and in velocity. If this is done, it turns out that the swings in the stock of money are in the opposite direction from those in velocity and so much larger in amplitude that they dominate the movements in money income. As a result, the long swings in prices mirror faithfully the long swings in the stock of money per unit of output. These long swings are much more marked in money income and in the nominal stock of money than in real income and in the real stock of money, which is to say that the long swings are largely price swings.

\section{B. CYCLICAL BEHAVIOR}

1. The real stock of money, like real income, conforms positively to the cycle; that is, it tends to rise during expansions and to fall, or to rise at a less rapid rate, during contractions. However, the amplitude of the movement in the real stock of money is decidedly smaller than in real income. If we allow for secular trends, a 1 per cent change in real income during a cycle is accompanied by a change in the real stock of money in the same direction of about one-fifth of 1 per cent.

It follows that income velocity tends to rise during cyclical expansions when real income is rising and to fall during cyclical contractions when real income is falling - that is, to conform positively. So far as we can tell from data that are mostly annual, velocity reaches both its peak and its trough at roughly the same time as general economic activity does.

2. Cyclical movements in money income, like the long swings, can be attributed to movements in the nominal stock of money and in velocity. If this is done, it turns out that the movements in the stock of money and in velocity are in the same direction and of roughly equal magnitude, so that neither can be said to dominate the movements in money income.

3. Table 1 summarizes the size of the cyclical movements in the variables used in the analysis, where the size of cyclical movement is measured by the excess of the rate of change per month during cyclical expansions over that during cyclical contractions.

\section{THE CONTRAST}

These findings are clearly in sharp contrast. Over long periods, real income and velocity tend to move in opposite directions; over reference cycles, in the same direction. Over long periods, 
changes in the nominal stock of money dominate, at least in a statistical sense, the swings in money income, and the inverse movements in velocity are of minor quantitative importance; over reference cycles, changes in velocity are in the same direction as changes in the nominal stock of money and are comparable in first instance by the monetary authorities or institutions and cannot be altered by the non-bank holders of money. The real stock of money is determined in the first instance by the holders of money.

This distinction is sharpest and least ambiguous in a hypothetical society in which money consists exclusively of a

\section{TABLE 1*}

Cyclical Movements in Income, Money Stock, Income Velocity, and PRices: Difference in Monthlly Rate of Change between REFERENCE EXPANSION AND CONTRACTION, ANNUAL ANALYSIS, 18701954, EXCLUDING WAR CYCLES

\begin{tabular}{|c|c|c|c|}
\hline & \multicolumn{2}{|c|}{ 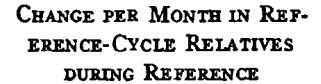 } & \multirow{2}{*}{$\begin{array}{c}\text { EXCESS OF } \\
\text { EXPANSION } \\
\text { OVER } \\
\text { CONTRACTION } \\
\text { (3) }\end{array}$} \\
\hline & $\begin{array}{c}\text { Expansion } \\
\text { (1) }\end{array}$ & $\begin{array}{c}\text { Contraction } \\
\text { (2) }\end{array}$ & \\
\hline \multicolumn{4}{|l|}{ Twelve mild depression cycles: } \\
\hline Money income............. & 0.64 & -0.07 & 0.71 \\
\hline Money stock. . . . . . . . . & .55 & .28 & 0.27 \\
\hline Income velocity $\ldots \ldots \ldots \ldots \ldots$ & .08 & -.32 & 0.40 \\
\hline Implicit price deflator. . . . . . . & .12 & -.02 & 0.14 \\
\hline 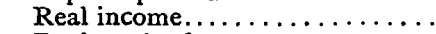 & .52 & -.05 & 0.57 \\
\hline Real stock of money . . . . . . . . & .43 & & 0.13 \\
\hline \multicolumn{4}{|l|}{ Six deep depression cycles: } \\
\hline Money income............. & .64 & -.97 & 1.61 \\
\hline Money stock. .............. & .60 & -.28 & 0.88 \\
\hline Income velocity $\ldots \ldots \ldots \ldots \ldots$ & .02 & -.69 & 0.71 \\
\hline Implicit price deflator. ........ & .16 & -.44 & 0.60 \\
\hline Real income............. & .46 & -.53 & 0.99 \\
\hline Real stock of money......... & 0.42 & 0.18 & 0.24 \\
\hline \multicolumn{4}{|c|}{ 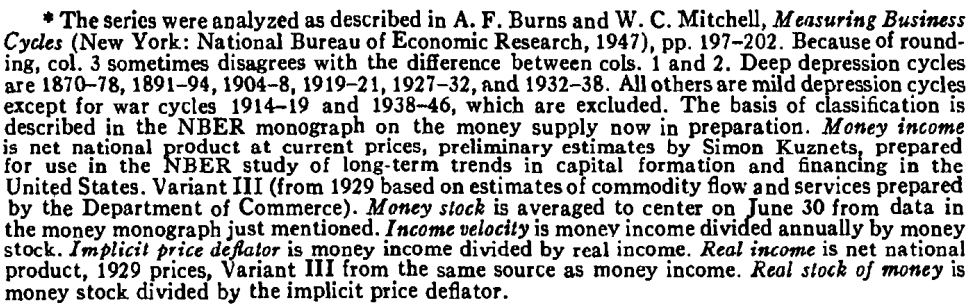 } \\
\hline
\end{tabular}

quantitative importance in accounting for changes in money income. I turn to an attempted reconciliation.

\section{A SUGGESTED EXPLANATION}

It is important to note at the outset an essential difference between the determinants of the nominal stock of money, on the one hand, and the real stock of money, on the other. The nominal stock of money is determined in the purely fiduciary currency issued by a single money-creating authority at its discretion. The nominal number of units of money is then whatever amount this authority creates. Holders of money cannot alter this amount directly. But they can make the real amount of money anything that in the aggregate they want to. If they want to hold a relatively small real quantity of money, they will individually seek to reduce their nominal 
cash balances by increasing expenditures. This will not alter the nominal stock of money to be held-if some individuals succeed in reducing their nominal cash balances, it will only be by transferring them to others. But it will raise the flow of expenditures and hence money income and prices and thereby reduce the real quantity of money to the desired level. Conversely, if they want to hold a relatively large real quantity of money, they will individually seek to increase their nominal cash balances. They cannot, in the aggregate, succeed in doing so. However, in the attempt, they will lower the nominal flow of expenditures, and hence money income and prices, and so raise the real quantity of money. Given the level of real income, the ratio of income to the stock of money, or income velocity, is uniquely determined by the real stock of money. Consequently, these comments apply also to income velocity. It, too, is determined by the holders of money, or, to put it differently, it is a reflection of their decisions about the real quantity of money that they desire to hold. We can therefore speak more or less interchangeably about decisions of holders of money to change their real stock of money or to change the ratio of the flow of income to the stock of money.

The situation is more complicated for the monetary arrangements that actually prevailed over the period which our data cover. During part of the period, when the United States was on an effective gold standard, an attempt by holders of money to reduce their cash balances relative to the flow of income raised domestic prices, thereby discouraging exports and encouraging imports, and so tended to increase the outflow of gold or reduce its inflow. In addition, the rise in domestic prices raised, among other things, the cost of producing gold and hence discouraged gold production. Both effects operated to reduce the nominal supply of money. Conversely, an attempt by holders of money to increase their cash balances relative to the flow of income tended to increase the nominal supply of money through the same channels. These effects still occur but can be and typically are offset by Federal Reserve action.

Throughout the period, more complicated reactions operated on the commercial banking system, sometimes in perverse fashion. For example, an attempt by holders of money to reduce cash balances relative to income tended to raise income and prices, thus promoting an expansionary atmosphere in which banks were generally willing to operate on a slenderer margin of liquidity. The result was an increase rather than a reduction in the nominal supply of money. Similarly, changes in the demand for money had effects on security prices and interest rates that affected the amount of money supplied by the banking system. And there were further effects on the actions of the Federal Reserve System for the period since 1914.

There were also indirect effects running in the opposite direction, from changes in the conditions of supply of money to the nominal quantity of money demanded. If, for whatever reason, money-creating institutions expanded the nominal quantity of money, this could have effects, at least in the first instance, on rates of interest and so on the quantity of money demanded, and perhaps also on money income and real income.

Despite these qualifications, all of which would have to be taken into account in a complete analysis, it seems useful to regard the nominal quantity of money as determined primarily by con- 
ditions of supply, and the real quantity of money and the income velocity of money as determined primarily by conditions of demand. This implies that we should examine the demand side for an initial interpretation of the observed behavior of velocity.

Along these lines, the changes in the real stock of money and in the income velocity of circulation reflect either (a) shifts along a relatively fixed demand schedule for money produced by changes in the variables entering into that schedule; (b) changes in the demand schedule itself; or $(c)$ temporary departures from the schedule, that is, frictions that make the actual stock of money depart from the desired stock of money. The rest of this paper is an attempt to see to what extent we can reconcile the secular and cyclical behavior of velocity in terms of $a$ alone without bringing in the more complicated phenomena that would be involved in $b$ and $c$.

One way to do so would be to regard the cyclical changes in velocity as reflecting the influence of variables other than income. In order for this explanation to be satisfactory, these other variables would have to exert an influence opposite to that of income and also be sufficiently potent to dominate the movement of velocity. Our secular results render this implausible, for we there found that income appeared to be the dominant variable affecting the demand for real cash balances. Moreover, the other variables that come first to mind are interest rates, and these display cyclical patterns that seem most unlikely to account for the sizable, highly consistent, and roughly synchronous cyclical pattern in velocity. Long-term corporate interest rates fairly regularly reached their trough in mid-expansion and their peak in mid-contraction prior to World War I.
Since then, the pattern is less regular and is characterized by shorter lags. Rates on short-term commercial paper also tend to lag at peaks and troughs, though by a briefer interval, and the lag has similarly shortened since 1921. Call-money rates come closer to being synchronous with the cycle, and this is true also of yields on long- and short-term government obligations for the six cycles for which they are available. Of the rates we have examined these are the only ones that have anything like the right timing pattern to account for the synchronous pattern in velocity. However, neither call-money rates nor government bond yields have been highly consistent in behavior from cycle to cycle. Even if they had been, it seems dubious that the effects of changes in these particular rates, or other unrecorded rates like them, would be sufficiently more important cyclically than secularly to offset the effects of countermovements both in other rates and in income. Furthermore, earlier studies that have attempted to explain velocity movements in these terms have had only limited success. ${ }^{4}$

A very different way to reconcile the cyclical and secular behavior of velocity is to regard the statistical magnitude called "real income" as corresponding to a different theoretical construct in the cyclical than in the secular analysis. This possibility was suggested by my work on consumption. In that field, too, it will be recalled, there is an apparent conflict between empirical findings for short periods and long periods: cross-section data for individual years suggest that the average propensity to consume is lower at highincome levels than at low-income levels; yet aggregate time-series data covering a long period reveal no secular decline in

E.g., see Selden, op. cit., pp. 195-202. 
the average propensity to consume with a rise in income. It turned out that this conflict could be reconciled by distinguishing between "measured" income, the figure recorded by statisticians, and "permanent" income, a longer-term concept to which individuals are regarded as adjusting their consumption. ${ }^{5}$

According to the permanent income hypothesis, when a consumer unit experiences a transitory increment of income, that is, when its measured income exceeds its permanent income, this transitory component is added to its assets (perhaps in the form of durable consumer goods) or used to reduce its liabilities rather than spent on consumption. Conversely, when it experiences a transitory decrement of income, it nonetheless adjusts consumption to permanent income, financing any excess over measured income by drawing down assets or increasing liabilities.

This theory of consumption behavior is directly applicable to that part of the stock of money held by consumer units rather than by business enterprises. The problem is how to interpret money holding. Much of the theoretical literature on "motives" for holding money suggests interpreting money holdings as one of the balance-sheet items that act as shock absorbers for transitory components of income; as an asset item that is increased temporarily when the transitory component is positive and that is drawn down, if necessary, to finance consumption when the transitory component is negative.

This interpretation may be valid for very short time periods. However, if it were valid for periods as long as a busi-

' See my $A$ Theory of the Consumption Function (a publication of the National Bureau of Economic Research) (Princeton: Princeton University Press, 1957). ness cycle, it would produce a cyclical behavior of velocity precisely the opposite of the observed behavior. Measured income presumably exceeds permanent income at cyclical peaks and falls short of permanent income at cyclical troughs. Hence cash balances would be drawn down abnormally at troughs and built up abnormally at peaks. In consequence, cash balances would fluctuate more widely over the cycle than income, and velocity would conform inversely to the cycle, falling during expansions and rising during contractions, whereas in fact it conforms positively.

An alternative is to interpret money as a durable consumer good held for the services it renders and yielding a flow of services proportional to the stock, which implies that the shock-absorber function is performed by other items in the balance sheet, such as the stock of durable goods, consumer credit outstanding, personal debt, and perhaps securities held. On this interpretation, the quantity of money demanded, like the quantity of consumption services in general, is adapted not to measured income but to permanent income. This interpretation is consistent with our secular results. The income figure we used in obtaining these is an average value over a cycle, which may be regarded as a closer approximation to permanent income than an annual value. In any case, the long time period covered assures that the movements in money are dominated by the movements in the permanent component of income. ${ }^{6}$ For the cyclical analysis, permanent income need not itself be stable over a cycle. It may well rise during expansions and fall during contractions. Presumably, however, it will rise less than measured income during expansions and fall

$$
\text { Ibid., pp. 125-29. }
$$


less during contractions. Hence, if money holdings were adapted to permanent income, they might rise and fall more than in proportion to permanent income, as is required by our secular results, yet less than in proportion to measured income, as is required by our cyclical results.

To put the matter differently, suppose that the demand for real cash balances were determined entirely by real permanent income according to the relation estimated in the secular analysis and that actual balances throughout equaled desired Dalances. Velocity would then fall during expansions and rise (or fall at a smaller rate) during contractions, provided that it was computed by dividing permanent income by the stock of money. But the numbers we have been calling "velocity" were not computed in this way; they were computed by dividing measured income by the stock of money. Such a measured velocity would tend to be lower than what we may call permanent velocity at troughs, because measured income is then lower than permanent income and would tend to be higher at peaks, because measured income is then higher than permanent income. Measured velocity might therefore conform positively to the cycle, even though permanent velöcity conformed inversely.

These comments apply explicitly only to consumer cash balances. However, they can readily be extended to business cash balances. Businesses hold cash as a productive resource. The question is whether cash is a resource like inventories, in which case it might be expected to fluctuate more over the cycle than current production, or like fixed capital, in which case it might be expected to fluctuate less and to be adapted to the longer-term level of production at which a firm plans to operate. This latter possibility involves a concept analogous to that of permanent income. If the observed positive cyclical conformity of velocity reflects wider movements in income than in both business holdings and consumer holdings, as seems likely in view of the changing importance of these two components and the consistent behavior of velocity, the answer must be that cash balances are analogous to fixed capital rather than to inventories and that some other assets or liabilities serve as shock-absorbers for business as for consumers.

The distinction between permanent and measured income can rationalize the observed cyclical behavior of income velocity in terms of a movement along a stable demand curve. It cannot by itself easily rationalize the behavior of real cash balances. Our secular analysis implies that real cash balances should conform positively to the cycle with an amplitude nearly twice that of permanent real income. Observed real cash balances do conform positively, but their amplitude, at any rate for cycles containing mild contractions, is so small that it seems implausible to regard it as larger than that in permanent real income. Put differently, it would take only very moderate changes in the index of prices, well within the margin of error in such indexes, to convert the positive conformity into inverted conformity.

The resolution is straightforward. We have not yet carried our logic far enough. If applied to both money income and real income, the distinction between measured and permanent income implies a corresponding distinction for prices. To put the matter in terms of economics rather than arithmetic, our analysis suggests that holders of cash balances determine the amount to hold in light of their longer-term income position rather than their momentary receipts - this is the 
justification for distinguishing measured from permanent income. By the same token, they may be expected to determine the amount of cash balances to hold in light of longer-term price movements - permanent prices, as it wererather than current or measured prices. Suppose, for example, prices were to double permanently or, alternatively, to double for day $\mathrm{X}$ only and then return to their initial level and that this behavior was correctly anticipated by holders of money. Holders of money would hardly want to hold the same nominal cash balances on day $\mathrm{X}$ in these two cases, even though prices were the same on that day. More generally, whatever the motives for holding cash balances, they are held and are expected to be held for a sizable and indefinite period of time. Holders of money presumably judge the "real" amount of cash balances in terms of the quantity of goods and services to which the balances are equivalent, not at any given moment of time, but over a sizable and indefinite period; that is, they evaluate them in terms of "expected" or "permanent" prices, not in terms of the current price level. This consideration does not, of course, rule out some adjustment to temporary movements in prices. Such movements offer opportunities of profit from shifting wealth from cash to other forms of assets and conversely, and they may affect people's expectations about future price levels. Like "permanent income," the "permanent" price level need not be-and presumably is not-a constant over time; it departs from the current price level in having a smoother and less fluctuating pattern in time but need not go to the extreme of displaying no fluctuations.

On this view, the current price level would presumably fall short of the permanent price level at troughs and exceed it at peaks of cycles; hence measured real cash balances would tend to be larger than permanent real cash balances at troughs and smaller at peaks. It follows that measured real cash balances would show a smaller cyclical movement than permanent real cash balances and, indeed, might conform inversely to the cycle, even though permanent real cash balances conformed positively.

\section{A SYMBOLIC RESTATEMENT}

The distinction between permanent and measured magnitudes can thus reconcile the qualitative behavior during reference cycles of both measured velocity-its tendency to conform positivelyand measured real cash balances-its tendency to show an exceedingly mild cyclical movement-with their behavior over secular periods. The crucial question remains whether it not only can reconcile the qualitative behavior but does in fact rationalize the quantitative behavior of these magnitudes. After all, an interpretation in terms of interest rates can also rationalize the qualitative results; we reject it because it appears likely to be contradicted on a more detailed quantitative level.

It will facilitate such a quantitative test to restate symbolically and more precisely the explanation just presented. Let

$Y$ be measured aggregate income in nominal terms;

$P$ be measured price level;

$M$ be aggregate stock of money in nominal terms, measured and permanent being taken throughout as identical;

$N$ be population, measured and permanent being taken as identical;

$Y_{p}, P_{p}$ be permanent nominal aggregate income and permanent price level, respectively; 
$y=\frac{Y}{P}$ be measured aggregate in$y_{p}=\frac{Y_{p}}{P_{p}}$ be permanent aggregate in coal terms; $M$ be measured aggregate $m=\frac{M}{P}$ stock of money in real $M$ be permanent aggregate $m_{p}=\frac{M}{P_{p}}$ stock of money in real $V=\frac{Y}{M}=\frac{y}{m}$ be measured velocity; $V_{p}=\frac{Y_{p}}{M}=\frac{y_{p}}{m_{p}}$ be permanent velocity.

In these symbols, the demand equation fitted to the secular data can be written thus:

$$
\frac{M}{N P_{p}}=\gamma\left(\frac{Y_{p}}{N P_{p}}\right)^{\delta}
$$

which expresses permanent real balances per capita as a function of permanent real income per capita, or in the equivalent form,

$$
m_{p}=\gamma N\left(\frac{y_{p}}{N}\right)^{\delta}=\gamma N^{1-\delta} y_{p}^{\delta},
$$

which expresses aggregate permanent real balances as a function of aggregate permanent real income and population, where $\boldsymbol{\gamma}$ and $\delta$ are parameters and $\delta$ was estimated to be approximately $1.8 .^{7}$

By definition,

$$
m=\frac{M}{P}=\frac{M}{P_{p}} \frac{P_{p}}{P}=\frac{P_{p}}{P} m_{p},
$$

so that still a third form of the demand equation is

$$
m=\frac{P_{p}}{P} \gamma N^{1-\delta} y_{p}^{\delta},
$$

7 The basic analysis holds, of course, whatever the precise form of the demand equation for money. I use this particular form for simplicity and because it gave a satisfactory fit to the available evidence. The whole analysis could, however, be restated in terms of a generalized demand function whose form was unspecified. which expresses aggregate measured real balances as a function of aggregate permanent real income, population, and permanent and measured prices.

This relation can also be expressed in terms of velocity. By definition, $V_{p}=$ $y_{p} / m_{p}$. Divide $y_{p}$ successively by the two sides of equation (2). This gives

$$
V_{p}=\frac{y_{p}}{m_{p}}=\frac{1}{\gamma} N^{\delta-1} y_{p}^{1-\delta}=\frac{1}{\gamma}\left(\frac{y_{p}}{N}\right)^{1-\delta} .
$$

By definition,

$$
V=\frac{Y}{M}=\frac{Y}{Y_{p}} \frac{Y_{p}}{M}=\frac{Y}{Y_{p}} V_{p},
$$

so that

$$
V=\frac{Y}{Y_{p}} \frac{1}{\gamma}\left(\frac{y_{p}}{N}\right)^{1-\delta}
$$

In interpreting equations (1), (2), (4), (5), and (7), it should be borne in mind that they will not, of course, be satisfied precisely by observed data. In consequence, at a later stage, I shall want to distinguish between observed values of, for example, measured velocity and the value estimated from, say, equation (7).

\section{TESTS OF THE EXPLANATION}

It has so far been sufficient to suppose only that the permanent magnitudes introduced-permanent income and permanent prices-fluctuate less over the cycle than the corresponding measured magnitudes. We can clearly go farther and ask how much less the permanent magnitudes must fluctuate in order to account for the quantitative, as well as the qualitative, average behavior of velocity and real cash balances. The answer may provide some internal evidence on the plausibility of the suggested explanation and will also provide a starting point for bringing external evidence to bear.

Consider the data for the mild depres- 
sion cycles shown in Table 1 and neglect the mild cyclical movements in population, so that aggregate and per capita values can be regarded as interchangeable. If measured and permanent magnitudes were treated as.identical, the income elasticity of 1.8 computed from the secular data would convert the 0.57 cyclical movement in real income into a movement of 1.03 in real cash balances demanded. The movement of 0.14 in the implicit price index would, in turn, convert this into a movement of 1.17 in money cash balances demanded. The actual movement in cash balances is 0.27 , or 23 per cent as large. Hence, to reconcile the secular and cyclical results, the cyclical movements in permanent income and permanent prices would each have to be 23 per cent of those in measured income and measured prices-a result that seems not implausible. For deep depression cycles, the corresponding figure turns out to be 37 per cent, which is equally plausible. Moreover, it seems eminently reasonable that this figure should be larger for deep, than for mild, depression cycles, since the deep depression cycles are longer on the average than the mild depression cycles. ${ }^{8}$

Of course, this test of intuitive plausibility is a weak one. To get a stronger test, we must introduce some independent evidence on the relation of permanent to measured magnitudes. One source of such evidence is the work on consumption that suggested the explanation under test. In deriving a consumption function from aggregate time-series data, I concluded that an estimate of permanent income-which I called "expected" income to distinguish it from the theoretical concept - was given by

$$
y_{p}(T)=\beta \int_{-\infty}^{T} e^{(\beta-a)(t-T)} y(t) d t .
$$

In words, an estimate of expected income at time $T$ is given by a weighted average of past incomes, adjusted for secular growth at the rate of $a$ per cent per year, the weights declining exponentially and being equal to $e^{\beta(t-T)}$, where $t$ is the time of the observation being weighted. The numerical value of

${ }^{8}$ Let $\dot{M}$ and $\dot{P}$ be the cyclical movements as measured in the final column of Table 1 in the nominal stock of money and in measured prices; let $\dot{m}_{p}$ and $\dot{P}_{p}$ be the cyclical movements in permanent real balances and permanent prices. Then, to a first approximation,

$$
\dot{M}=\dot{m}_{p}+\dot{P}_{p},
$$

since the stock of money is the product of permanent real cash balances and the permanent price level. Using the demand equation (2), we get

$$
\dot{m}=1.8 \dot{y}_{p},
$$

where $\dot{y}_{p}$ is the cyclical movement in permanent real income (recall that we are neglecting any cyclical movement in population, so $\dot{y}_{p}$ also equals the movement in permanent real per capita income).

Let

$$
\begin{gathered}
\dot{y}_{p}=k \dot{y}, \\
\dot{P}_{p}=k^{\prime} \dot{P},
\end{gathered}
$$

where $\dot{y}$ is the cyclical movement in measured real income and $k$ and $k^{\prime}$ are unspecified constants to be determined. Substituting equations (ii), (iii), and (iv) in equation (i) gives

$$
\dot{M}=1.8 k \dot{y}+k^{\prime} \dot{P} .
$$

At first glance, it seems possible to derive both $k$ and $k^{\prime}$ from one set of data by deriving a similar equation starting with an identity like (i) expressing measured velocity in terms of permanent velocity. However, the resulting equation is identical with eq. (v), thanks to the definitional relations connecting velocity, money, and income.

The calculations in the text implicitly assume that $k=k^{\prime}$ in eq. (v). Separate estimates for $k$ and $k^{\prime}$ require two sets of data. One possibility is to assume that $k$ and $k^{\prime}$ differ but that each is the same for mild and for deep depression cycles, an assumption that seems less plausible than the one made in the text that $k=k^{\prime}$. This calculation yields an estimate of 0.11 for $k$ and 1.15 for $k^{\prime}$. The value for $k^{\prime}$ contradicts the concepts of permanent and measured prices that underlie the analysis. 
$\beta$ was estimated to be 0.4 ; of $a, 0.02 .{ }^{9} \mathrm{It}$ is by no means necessary that the concept of permanent income that is relevant in determining total consumption expenditures should also be the one that is relevant in determining cash balances. ${ }^{10}$ But it would not be at all surprising if it were. On the assumption that it is, we can get independent estimates of the percentages cited in the previous paragraph by computing estimates of permanent real income and permanent prices from the corresponding observed annual series, using the weighting pattern just described.

The results of these computations are summarized in columns 1,2 , and 3 of Table 2.1 The agreement between the

\footnotetext{
${ }^{9}$ Friedman, $A$ Theory of the Consumption Function, pp. 146-47.

${ }^{10}$ See ibid., pp. 150-51.
}

${ }^{11}$ These results at first seemed to me relevant also to the choice between the two alternative assumptions used above-the one in the text that $k=k^{\prime}$ and the one noted in footnote 8 , that $k \neq k^{\prime}$ but that $k$ is the same for mild and deep depression cycles and so is $k^{\prime}$. On this issue, the result is unambiguous. The entries in col. 3. clearly speak for the first assumption.

However, James Ford has pointed out to me that this result is largely a consequence of an assumption made in estimating permanent income and prices, namely, the use of the same value of $\beta$ for both. There is no independent empirical evidence for this assumption, and hence results based on it can give no independent evidence for the essentially equivalent assumption that $k=k^{\prime}$.

For the special case in which the measured magnitude is given by a sine curve, the relative amplitude of a permanent and a measured magnitude when the permanent is estimated by a weighted average of the measured is determined entirely by the value of $\beta$ and the duration of the cycle. For $\beta=0.4$ and a cycle 43 months in length, which is the average length of the mild depression cycles, the relative amplitude for the sine curve is 0.22 . For $\beta=0.4$ and a cycle 47.5 months in length, the average length of the deep depression cycles, the relative amplitude for the sine curve is 0.25 . These results are fairly similar to the computed values in Table 2. They differ enough, however, to suggest that the departure from a sine curve affects the results appreciably. tions.

I am indebted to James Ford for these calcula- estimates in column 3 so obtained and the estimates constructed above from internal evidence alone is very good-the two differ by only 15-30 per cent, even though they are based on independent bodies of data and even though the weights used in estimating the permanent magnitudes directly were derived for another purpose and rest on still other data. Moreover, the discrepancy is consistent; the difference between deep and mild depression cycles is in the same direction and of roughly the same magnitude for both columns.

These results are sufficiently encouraging to justify going beyond this indirect test and seeing how far our interpretation is consistent not only with the size of the cyclical movement in cash balances and measured velocity but also with their entire cyclical patterns and not only on the average but also cycle by cycle.

In order to perform this test on a fully consistent basis, we first recomputed the secular demand equation, using as the independent variable the cycle averages of estimated permanent income rather than measured income. This substitution slightly raised the correlation coefficient, thus giving a minor bit of additional evidence in favor of the permanent income interpretation. It also raised slightly the estimated elasticity of demand, but not by enough to change the numerical value to the number of significant figures given above.

The resulting calculated equation for nominal cash balances is

$$
M^{*}=(0.00323)\left(\frac{y_{p}}{N}\right)^{1.810} N P_{p},
$$

and, for measured velocity,

$$
V^{*}=\frac{1}{0.00323}\left(\frac{y_{p}}{N}\right)^{-0.810} \frac{Y}{Y_{p}},
$$


where the asterisks are used to indicate values computed from the equation rather than directly observed. These equations, it will be recalled, were estimated from average values over whole reference cycles. ${ }^{12}$

From these equations, one can estimate for each year separately, from the corresponding annual data, desired cash balances and the value of measured velocity that would be observed if actual cash balances equaled desired balances as so estimated. I shall call these "computed cash balances" and "computed measured velocity."'13

The estimates of computed measured velocity are plotted in Chart I, along with observed measured velocity. In

TABLE 2*

\section{Two Estimates of Cyclical Movements of Permanent Real INCOME AND PRICES AS PERCENTAGes OF THOSE OF MEASURED REAL INCOME AND Prices, Reference Cycles 1870-1954, Excluding War CyCles}

\begin{tabular}{|c|c|}
\hline $\begin{array}{r}\text { ExcEss } \\
\text { MONTH IN }\end{array}$ & $\begin{array}{l}\text { NGE PER } \\
\text { NCE-CYC }\end{array}$ \\
\hline E LATIV & \\
\hline & NTR \\
\hline $\begin{array}{l}\text { Permanent } \\
\text { Magnitude }\end{array}$ & $\begin{array}{l}\mathrm{Me} \\
\mathrm{Mag}\end{array}$ \\
\hline
\end{tabular}

(1)

0.11

.02

Real income...........

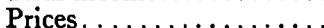

Six deep depression cycles:

Real income..............

Prices
(2)

0.57

.14

.99
Permanent as PerCENTAGe OF Measured Ratio

Permanent Estimated Estimated from Money Separately Equations

(3)

19

16

23

23

29

30
37

37

* The sources for the columns are as follows (cycles grouped as in Table 1):

1. Permanent real income and permanent prices were estimated as described in the text, using Kuznets' data (see note to Table 1). These da ta begin in 1869. To obtain an estimate of the permanent magnitude in 1869, measured figures covering the years 1858-69 are required, the weights assigned declining exponentially. Measured figures were therefore extrapolated: for real income by assuming a constant rate of growth of 3.5 per cent per year; for implicit prices by assuming that in each of the years 1858-68 they bore the same relation to the wholesale price index as in 1869.

2. Table 1, col. 3 .

3. Column 1 divided by col. 2, the figures in each case being carried to an additional place.

4. Values from Table 1 , col. 3 , were substituted in the expression $\dot{M} /(1.82 \dot{y}+\dot{P})$, where $M$ is money stock, $y$ is real income, $P$ is implicit price deflator, and the dot on top means "excess of change per month in reference-cycle relatives during reference expansion over that during reference contraction."

12 The numerical values given were computed from combined data for trough-to-trough and peakto-peak averages. However, separate regressions for each set of averages are almost identical.

${ }^{13}$ To make these calculations, estimates of $Y$, $Y_{p}, y_{p}, P_{p}$, and $N$ are needed. Measured money income, $Y$, was taken to be Kuznets' annual net national product in current prices adjusted for wartime periods; $Y_{p}$ was computed by applying eq. (8) to this same series, except for a minor adjustment in level; $y_{p}$, by applying eq. (8) to Kuznets' net national product in constant prices similarly adjusted, and again with a minor adjustment in level; $P_{p}$ by applying eq. (8) to the price index implicit in computing net national product in constant prices; and $N$ was taken as the mid-year population of the United States as estimated by the Census.

Equation (8) with $\beta=0.40$ and $a=0.02$ implies that expected income is 1.05 times the weighted average of actual income, where the weights are the declining exponential weights inside the integral of eq. (8), adjusted to sum to unity. When permanent net national product per capita in constant prices was computed in this way, it turned out that the geometric mean of the ratios of the cycle bases of real measured net national product per capita to the cycle bases of permanent net national product in constant prices so computed was 1.057. This factor of 1.057 was used to adjust the level of the latter series rather than the 1.05 strictly called for by eq. (8) and was used also for permanent net national product in current prices. The logical implication of employing the same multiple for net national product in constant and current prices is that a was treated as zero for prices alone. None of these adjustments is of any moment for the present analysis, since they affect only the level of the series and hence all cancel out when cycle relatives are computed. 
judging this figure, it should be borne in mind that the computed velocities were not obtained by trying to fit these observed velocities directly. They were obtained from a correlation for forty-one overlapping cycle bases-averages of groups of years varying in number from two to seven-plus a formula for estimating permanent income derived from an the secular finding. What is added by this chart is the relation between yearto-year movements. The secular results in no way insure that these will correspond; still, if anything, the computed velocity series mirrors the year-to-year cycles in observed velocity even more faithfully than it does the longer-term changes.

CHART I

Observed and Computed Measured Veloctty, AnNualdy, 1869-1957

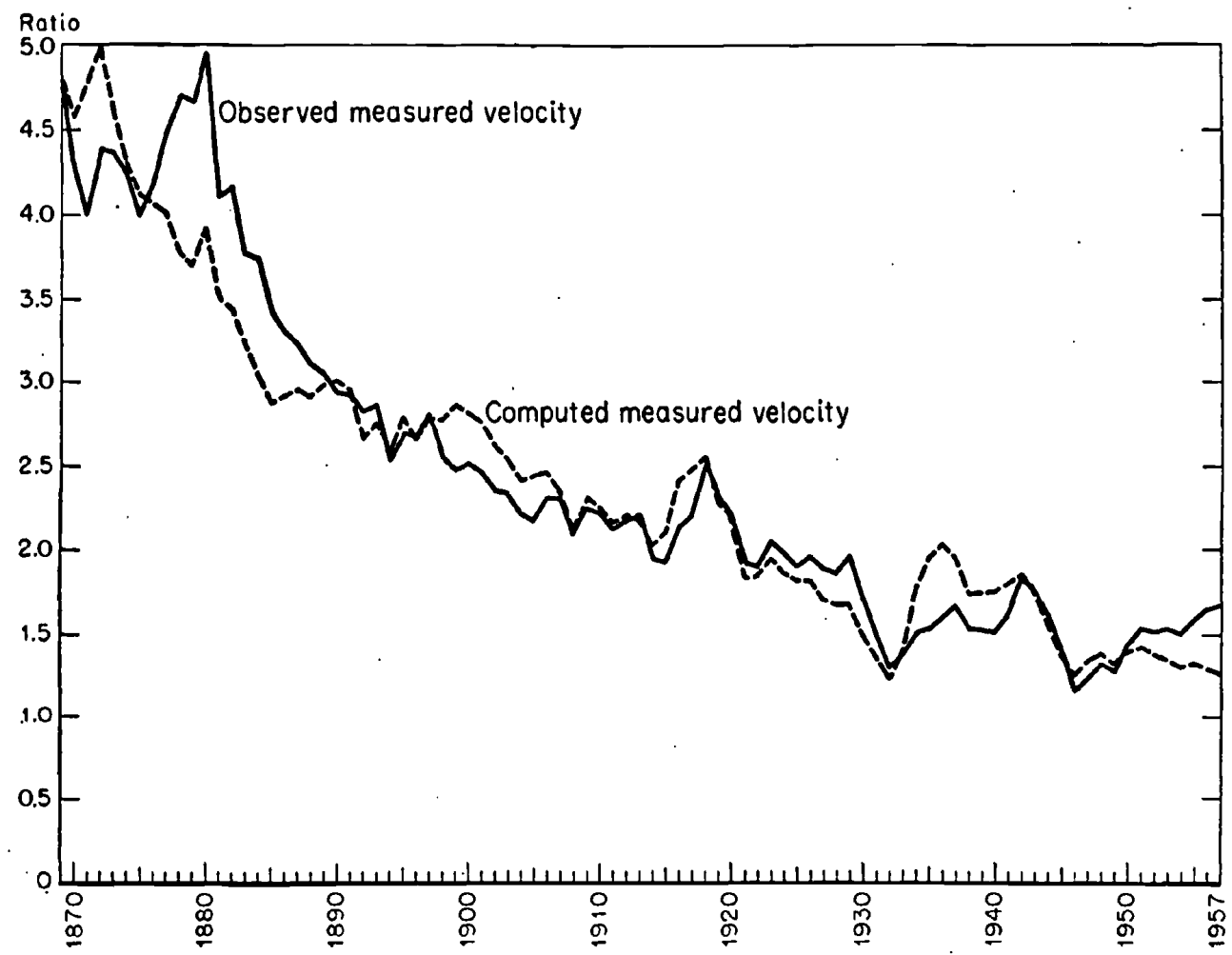

analysis of the relation of consumption expenditures to income plus a theoretical linkage between these two, summarized in equations (9) and (10). The high correlation between the cycle bases insures a close connection between the longerterm movements in computed and measured velocity; in this respect, Chart $I$ is simply a repetition in a different form of
In order to isolate the cyclical aspect of the analysis, we have computed reference-cycle patterns of computed measured velocity and computed cash balances, thereby eliminating entirely the part of Chart I that repeats the secular finding. Chart II gives the referencecycle patterns of computed and observed measured velocity cycle by cycle, and 


\section{CHART II}

Observed and Computed Measured Velocity, Reference-Cycle Patterns, 1870-1954

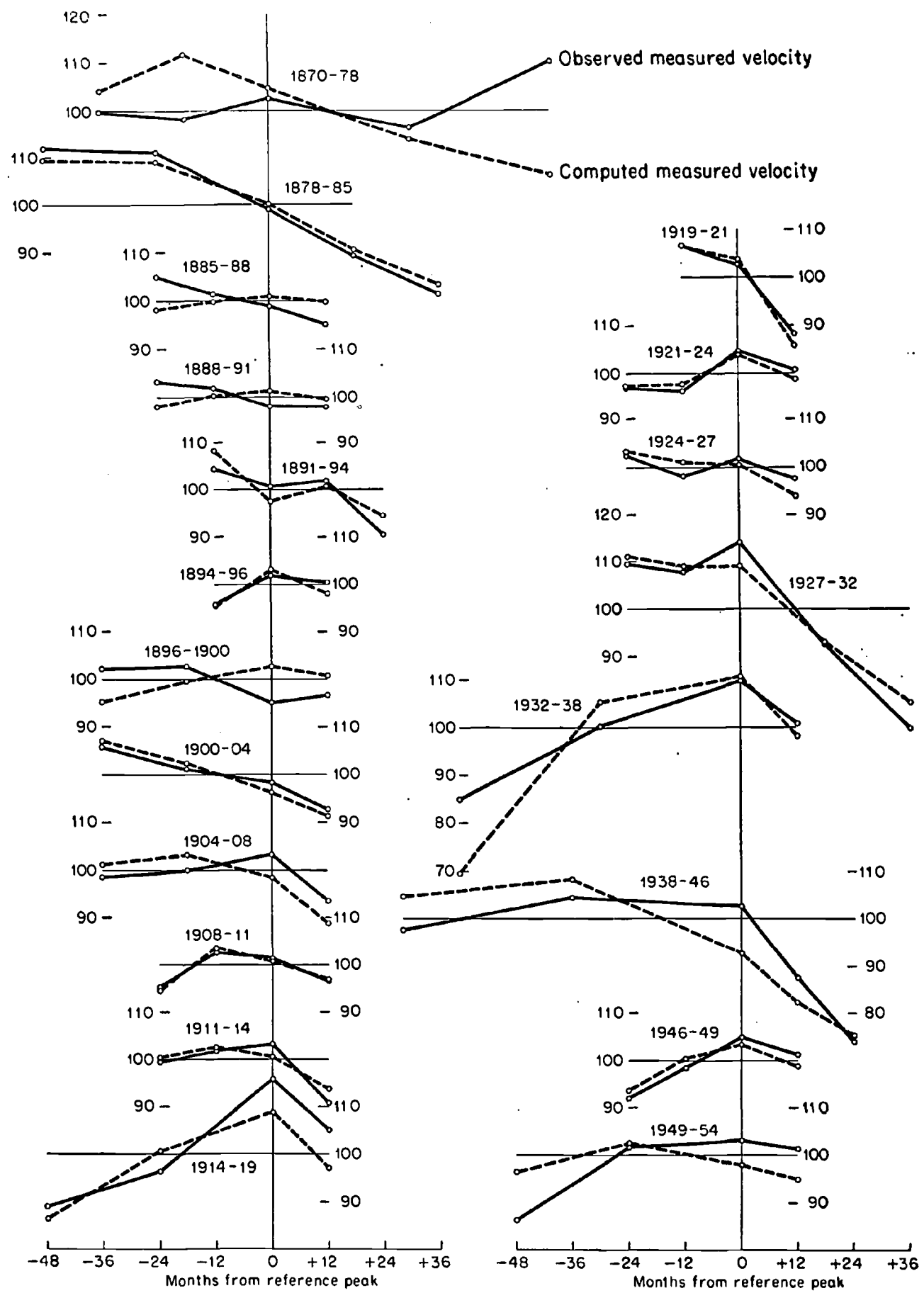

Note: These are reference-cycle relatives computed in the course of the cyclical analysis of the data shown in Chart I (see A. F. Burns and W. C. Mitchell, Measuring Business Cycles [New York: National Bureau of Economic Research, 1946], pp. 197-202). 
Chart III gives average patterns for the mild and deep depression cycles, for both cash balances and measured velocity. It is clear from these that my interpretation accounts for the bulk of the fluctuations in observed measured velocity. The average pattern of computed measured velocity duplicates almost perfectly that for observed meas- that this purely statistical interpretation of the findings is not valid. The cashbalance patterns agree about as closely as the velocity patterns.

These results give strong support to the view that cyclical movements in velocity largely reflect movements along a stable demand curve for money and that the apparent discrepancy between

\section{CHART III}

Observed and Computed Money Stock and Measured Velocity, Average ReferenceCycle Patterns, Mudd and Deep Depression Cycles, 1870-1954

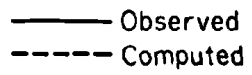

Panel A. Money Stock

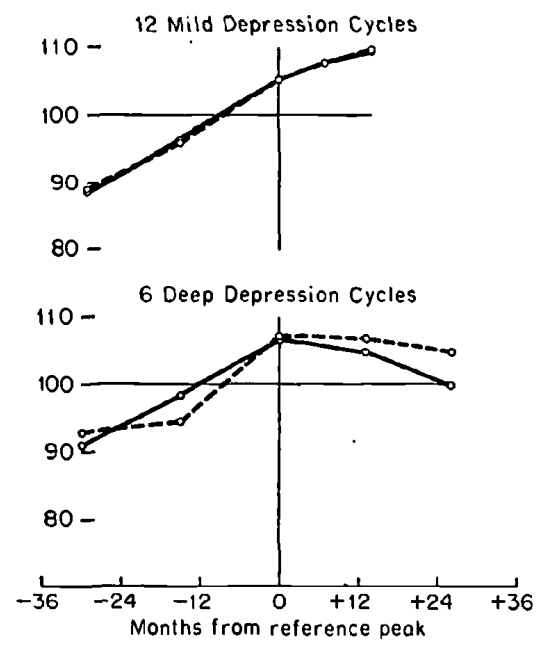

NorE: Cycles are grouped as in Table 1. ured velocity for the mild depression cycles and corresponds very closely to that for the deep depression cycles. The cycle-by-cycle patterns demonstrate that this coincidence is not simply in the averages. This closeness might reflect the use of the same values of measured income in both the observed and the computed velocities, in which case it could be regarded as largely spurious. The cashbalance patterns are included in Chart III to test this possibility. They demonstrate the secular and the cyclical results reflects a divergence between measures of income and of prices constructed by statisticians for short periods and the magnitudes to which holders of money adjust their cash balances.

\section{v. IIMITATIONS OF THE EXPLANATION}

Important though this explanation is, it cannot be the whole of the story, since it fails to account for some of the most important of our findings about the be- 
havior of money balances. If the desired real stock of money were determined entirely by permanent real income and if the desired stock were always equal to the actual stock, then the actual real stock (computed in terms of permanent prices) would have a cyclical pattern that duplicated the pattern of permanent real income except for amplitude. Now our evidence suggests that permanent real income conforms positively to the cycle and is either synchronous or lags at the turning points. Hence real cash balances computed at permanent prices would do likewise. Nominal cash balances equal these real cash balances times permanent prices, and our evidence suggests equally that permanent prices conform positively to the cycle either synchronously or with a lag. This train of reasoning therefore implies that, under the supposed conditions, nominal cash balances would conform positively to the cycle and would be either synchronous or lag at the turning points. Yet one of the major findings of the broader study of which the results reported in this paper are a part is that the nominal stock of money, adjusted for trend, tends to lead at both peaks and troughs. Hence there is a residual element in the cyclical behavior of velocity that requires explanation.

A satisfactory analysis of this residual element requires the use of monthly rather than annual data. Annual data are unduly crude for studying timing relationships. For example, the cyclical patterns of the observed money stock in Chart III, Panel $A$, reveal no average lead; yet our more detailed analysis of monthly money data establish such a lead, after adjustment for trend, beyond any reasonable doubt.

It may nevertheless be worth examining the residual element in the annual data as a first step. This residual element is approximated in Chart IV by the ratio of the observed measured velocity to computed measured velocity. This ratio varies very much less over the cycle than measured velocity itself, and hence the movements it measures tend to be concealed by the movements in velocity arising out of the discrepancy between measured and permanent income. Yet our analysis of the stock of money suggests that this residual element may play a critical cyclical role. Indeed, perhaps the major significance of our analysis of velocity is that it enables us to extract this residual element, to eliminate the largely spurious movements of velocity that have hitherto masked the economically significant movements.

For deep depressions, the residual element has a clearly marked cyclical pattern: During expansion, the residual element at first falls, then rises, reaching a trough in mid-expansion. During contractions, the behavior is harder to determine, because one cycle-the earliest, from 1870 to 1878 - has a major influence on the pattern for all cycles and the figures for this cycle are highly dubious. ${ }^{14}$ If this cycle is omitted, the pattern for contractions is a mild fall from peak to mid-contraction and a sharper fall thereafter.

The residual element varies much less, on the average, for mild depression cycles than for deep depression cycles. Such cyclical movement as it does show is similar to that for deep depression cycles during expansion and just the re-

14 The problem is in the income estimates for the early period. These are characterized by an extraordinarily rapid rate of increase from 1869 to 1879. Other evidence suggests that this is at least partly a statistical artifact, reflecting the extreme paucity of reliable data for estimating income for this period. 


\section{Ratio of Observed to CoMputed Measured Velocity, Compared with Other Economic Variables, Average Reference-Cycle Patterns, Muld aNd Deep DePression Cycles, 1870-1954}

Panel A. Interest Rates on Private Obligations, 1870-1954

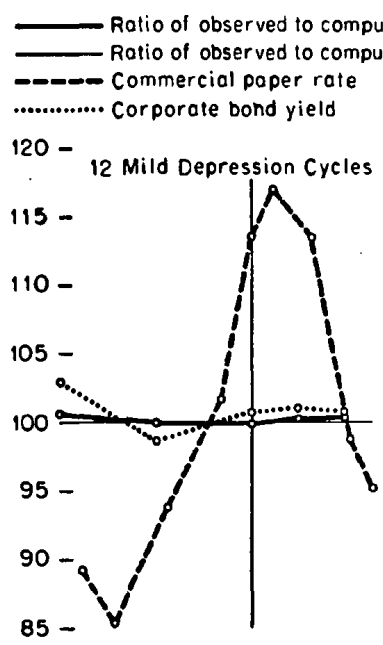

6 Deep Depression Cycles -130

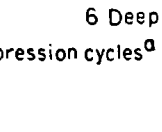

ed measured velocity

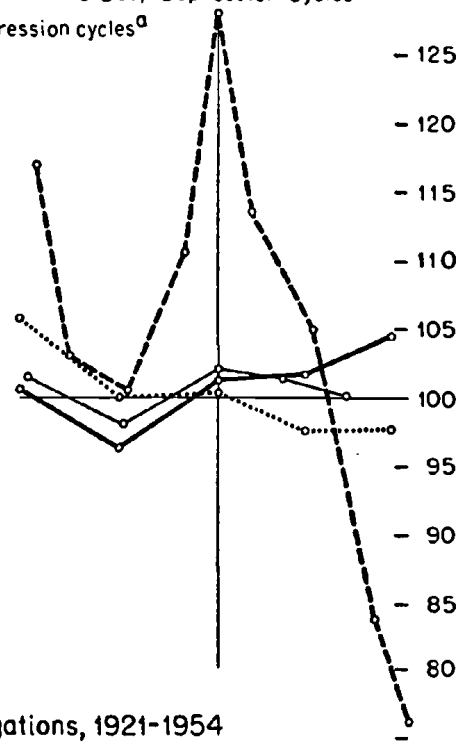

Panel B. Yields on Government Obligations, 1921-1954
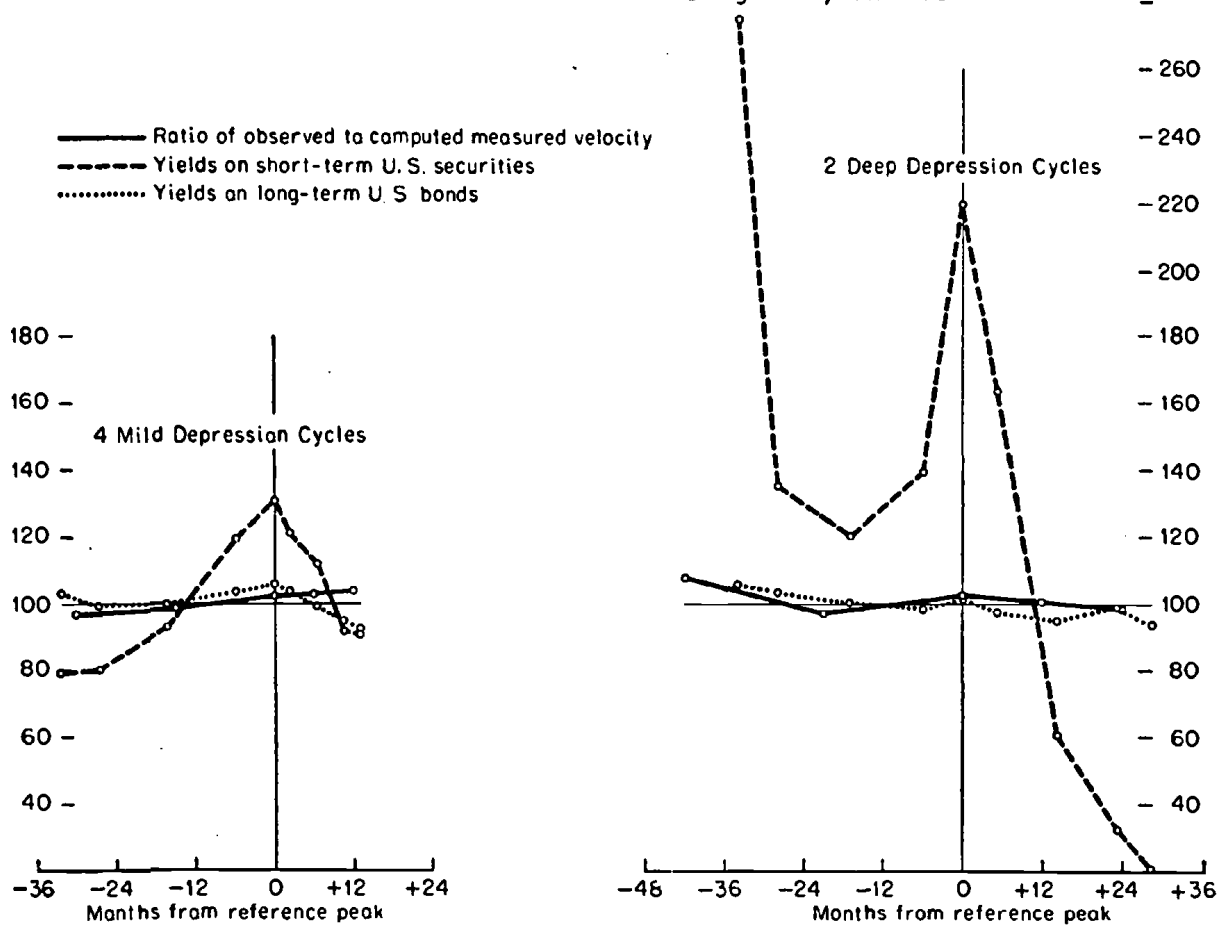

Ratio of observed to computed measured velocit

- Yields on short-term U.S. securities

............. Yields an long-term U S bonds

Nore: Vertical scales are in reference-cycle relatives, except scale for prices in Panel $C$, which is in rate of change of reference-cycle relatives per month. The scale of reference-cycle relatives in Panel $B$ is one-fourth that in Panel $A$, and the scale in Panel $C$ is two and a half times that in Panel $A$.

- Excluding 1870-78. 


\section{CHART IV-Continued}

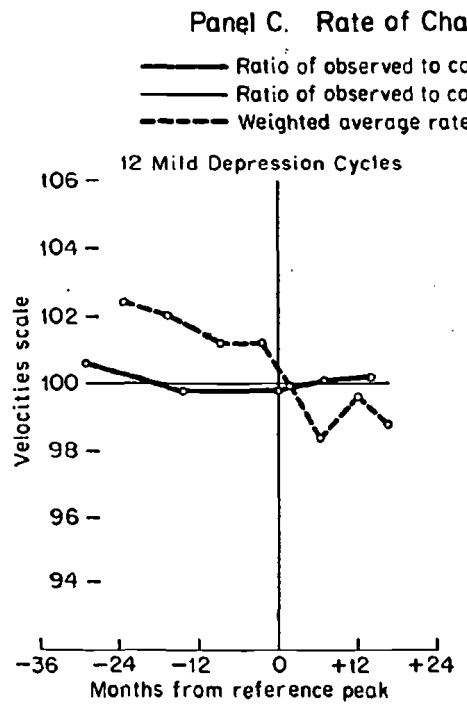

verse of that for deep depression cycles during contraction. This residual element is the cyclical component in cash balances that cannot be explained simply by a movement along a univariate demand curve in response to a cyclical movement in permanent income. It is perhaps not surprising that this component should be so much larger for deep than for mild depression cycles. In the mild depression cycles, there is a relatively small cyclical movement in general, which presumably means that there are only relatively small movements in whatever other variables operate to produce a discrepancy between desired cash balances as judged from income alone and actual cash balances.

What are these other variables? The obvious candidates are measures of the return on other assets that could be held instead of money. One alternative to holding money is to hold securities; another, to hold physical goods. The return to the first is measured by the rate of return received on the securities. The re- turn to the holding of physical goods is measured by the rate of change of prices minus storage costs; and either of these terms may be positive or negativeprices may rise or fall and storage of goods may yield a convenience return in excess of costs of handling and maintenance. In either case, these returns must be compared with those on money, which may be positive, as when interest is paid on deposits, or negative, as when service charges are incurred.

In our secular analysis, we have found that the yield on corporate bonds is correlated with the real stock of money and velocity in the expected direction: a rise in the bond yield tends to reduce the real stock of money demanded for a given real income-that is, to raise velocity-and conversely. Bond yields, however, play nothing like so important and regularly consistent a role in accounting for changes in velocity as does real income. The short-term interest rate was even less highly correlated with velocity than the yield on corporate bonds. 
Chart IV is designed to provide a rough test whether these secular results carry over to cyclical movements. In addition to the ratio of observed measured velocity to computed measured velocity, which is the residual element we are seeking to explain, Chart IV also shows the average reference-cycle patterns of corporate bond yields as derived from annual data, of commercial paper rates as derived from monthly data (Panel $A),{ }^{15}$ and of the yields on short- and long-term United States securities, as derived from monthly data (Panel $B){ }^{16}$ Panel $A$ covers the whole period 18701954, excluding only war cycles; Panel $B$ covers only the six non-war cycles after 1921, since yields on United States securities are not readily available for the earlier cycles.

Short-term rates have, of course, a much larger cyclical amplitude than long-term rates, which in turn have

${ }^{15}$ The corporate bond yield data through 1900 are railroad bond yields from F. R. Macaulay, Some Theoretical Problems Suggested by the Movements of Interest Rates, Bond Yields and Stock Prices in the United States since 1856, a publication of the National Bureau of Economic Research (New York, 1938), pp. A145-A152, col. 5, with 0.114 per cent arithmetic addition to raise them to the level of the following segment. After 1900 the data are "Basic Yields of Corporate Bonds to 50 Years Maturity," from Historical Statistics of the Uniled States, 1789-1945 (Bureau of the Census), p. 279; Continuation to 1952 of Historical Statistics, p. 36; Statistical Abstract of the United States, annually from 1953. Commercial paper rates in New York City, monthly, through January, 1937, are from Macaulay, op. cil., pp. A145-A161; thereafter, monthly averages of weekly figures from Bank and Quotation Record of the Commercial and Financial Chronicle. This series was seasonally adjusted through December, 1933. No seasonal adjustment has been necessary since.

${ }^{16}$ Yields on short-term United States securities are from Banking and Monetary Statistics, p. 460, and Federal Reserve Balletin, monthly issues, May, 1945 , to May, 1948, and September, 1950, to December, 1954. This series was seasonally adjusted, 192030, 1951-54. Yields on long-term United States securities are from the same sources and are unadjusted. roughly the same amplitude as the residual element in velocity. These differences in amplitude are of no special significance for our purpose except as they reflect the consistency of the cyclical pattern, since the effect of a change in interest rates depends not only on the size of the change but also on the elasticity of the response of cash balances to a change. Volatility of rate can be offset by a small elasticity of response and vice versa. The differences in amplitude do, however, make it more difficult to read the chart and tend somewhat to obscure the similarity or divergence in pattern that is of major interest.

The most striking feature of the charts is the high degree of similarity between the pattern of interest rates and that of the residual element of velocity during the expansion phase of deep depression cycles. Long and short rates and rates on private and public obligations all show much the same pattern for this phase, and the pattern of all four is similar to the pattern in the residual element in velocity: interest rates are high at the initial stage of expansion, and so is velocity, which is an appropriate response to a high rate of return on noncash assets; interest rates then decline to mid-expansion, and so does velocity; interest rates then rise to the peak of the cycle, and so does velocity.

There is no such unanimity of movement for the remaining phase of the deep depression cycles or for the mild depression cycles. For these phases, there is, at best, a family similarity between the movements in rates and those in the residual element in velocity. During the contraction phase of deep depression cycles, short and long rates diverge, short rates declining throughout, long rates leveling off or recovering in mid-contrac- 
tion. The residual element behaves rather more like short rates, if we abstract from the unusual behavior during the $1870-78$ cycle, but the similarity is not close in detail. For mild depression cycles, the cyclical movements in short and long rates are fairly similar, the main differences being a shorter lag in commercial paper rates at peaks and troughs than in the corporate bond yield. For the period as a whole ( $\operatorname{Panel} A$ ), the cyclical movement in the residual element, though fairly clear, is so small that no very precise comparison is justified; for the period since 1921 (Panel $B$ ), it is almost non-existent, the average reference-cycle pattern being dominated by an intracycle trend.

A number of empirical studies have demonstrated that the rate of change of prices has an important effect on the quantity of money demanded during periods of considerable instability of prices-as during hyperinflations or major and long-continued inflations. ${ }^{17}$ These studies suggest, further, that the expected rate of change of prices, which is the variable that directly influences the demand for money, can be regarded as derived largely from past experience with the actual movement of prices and that it changes more smoothly than actual prices; it is something like the rate of change in what I earlier designated "permanent" prices. These findings imply that any changes in the expected rate of change of prices during periods of relative price stability will be small, perhaps too small to have any appreciable effect. And this is, indeed, the conclusion

\footnotetext{
${ }^{17}$ See Phillip Cagan, "The Monetary Dynamics of Hyperinflation," in Milton Friedman (ed.), Siudies in the Quantity Theory of Money, pp. 25-117. The same relation has been documented for other countries and episodes in a number of unpublished studies done in the Workshop on Money and Banking of the University of Chicago.
}

reached by Richard Selden in his study of the behavior of velocity. ${ }^{18}$

As a further check on this conclusion, we have plotted in Chart IV, Panel $C$, the rate of change of prices from reference stage to reference stage. This is derived from the nine-stage reference-cycle patterns of the monthly wholesale price index ${ }^{19}$ by dividing the difference between successive average standings by the average time interval between them. The resulting eight rates of change per month are plotted at the mid-points of the corresponding intervals. Since these are the actual rates of change, they presumably vary more than expected rates of change and, in addition, may lead the latter in time. However, one might expect enough similarity between the actual rates of change and the expected rates of change to permit the detection of any moderately close relation between expected rate of change and the residual element in velocity.

Interestingly enough, the results largely duplicate those for interest rates. For the expansion phase of the deep depression cycles, there is the same striking agreement in pattern between the rate of change of prices and the residual element in velocity as there is between interest rates and the residual element. There is only slightly less similarity in pattern for the expansion phase of mild depression cycles. There is no systematic relation for the contraction phase of either group of cycles.

This analysis, based as it is on annual velocity data and on a comparison solely

${ }^{18}$ Selden, op. cit., p. 202.

${ }^{19}$ Historical Statistics of the United States, 17891945 (Warren-Pearson series, 1870-89; B.L.S. series, 1890-1945 [Bureau of the Census]), p. 344; Continuation to 1952 of Historical Statistics, p. 47; thereafter, U.S. Department of Labor, Bureau of Labor Statistics, Wholesale (Primary Market) Price Index, monthly issues. 
of average reference-cycle patterns, is too crude to be at all decisive. Yet the results are most suggestive. If the cyclical patterns of interest rates and the rate of change in prices are compared with the pattern of measured velocity itself (Chart III, Panel $B$ ), there is no clear relation-as we noted at the outset in explaining why an alternative reconciliation of the secular and cyclical behavior of velocity is required. When the comparison is made instead with the residual element of velocity-that part of the movement in measured velocity that is accounted for neither by the effect of changes in permanent income on desired cash balances nor by the discrepancy between measured and permanent income - there is a striking consistency for one phase of one set of cycles, and at least a family resemblance elsewhere, though, of course, not without considerable irregularity. These results are of the kind that might be expected if the returns on alternative ways of holding assets were the chief factor other than permanent income affecting desired cash balances. Of course, they do not demonstrate that this is so. They might, for example, reflect accidental concurrence of movement in just a few cycles. And they do not provide any estimate of the quantitative strength of the connection. But they certainly justify further research in this direction. The main requirements for such research are the use of monthly data on velocity or indicators of velocity and the examination of cycle-by-cycle relations and not simply relations between average patterns.

\section{CONCLUSION}

The results summarized in this paper have implications for the theory of money, the study of business cycles, and the conduct and possibilities of monetary policy.

In the theory of money, much emphasis has been placed on different "motives" for holding money - the "transactions" motive, the "speculative" motive, and the "assets" or "precautionary" motive being the three commonly distinguished. The transactions motive is often regarded as implying something of a quasi-mechanical relation between cash balances and the flow of payments and is frequently given priority of importance as well as place. Our results cast serious doubt on the acceptability of this emphasis. In the first place, the cyclical results make it clear that changes in cash balances over short periods are adapted to magnitudes less volatile than the volume of transactions. In the second place, the secular decline in income velocity is hard to explain in terms of transactions. It is dubious that there has been any secular increase in the ratio of transactions to income large enough to explain the growth in the ratio of money balances to income that has occurred. Further, improvements in transportation and communication, let alone in financial organization, have almost surely reduced any mechanical requirement for cash balances per unit of transactions-indeed, it was on these grounds that Irving Fisher implied nearly half-a-century ago that velocity was likely to increase secularly and that others have since expressed similar views. ${ }^{20}$

Our findings equally cast doubt on the importance of the so-called speculative motive. One would expect this motive to be subject to wide eyclical variations and hence, if it dominated the demand for money, to lead to correspondingly

${ }^{20}$ Irving Fisher, The Purchasing Power of Money (rev. ed.; New York, 1913), pp. 79-88. 
wide cyclical variations in desired cash balances, whereas we observe the reverse.

The assets or "precautionary" motive is in a different state. Permanent income can be regarded as a concept closely allied to wealth and indeed as an index of wealth, provided that we count both human and non-human sources of income as components of total wealth. Along these lines, our results can be interpreted in either of two ways. One is that the relevant asset motive is equivalent to a consumption or income motive. As permanent income, which is to say, total wealth, rises, consumer units expand their expenditures on some items disproportionately-we term these items "luxuries." On this interpretation, the services rendered by money can be included among these luxuries. The other interpretation is more nearly an asset motive proper. It is that the holdings of cash are linked not to total wealth but primarily to non-human wealth and that, as permanent income rises, the total value of non-human wealth rises more rapidly than permanent income, either because such a more rapid rise is a necessary condition for a rise in income or because it corresponds to the preferences of individuals as their total wealth rises. Unfortunately, the available evidence on the secular or cyclical behavior of the ratio of non-human wealth to income is inadequate to provide a test of this explanation. ${ }^{21}$ On either interpretation, however, our results suggest that motivations and variables linked with assets are the most fruitful category to explore - that the most fruitful approach is to regard money as one of a sequence of assets, on a par with bonds, equities,

${ }^{21}$ Raymond Goldsmith's estimates in $A$ Study of Savings (Princeton, N.J., 1955) suggest that, if anything, the ratio of non-human wealth to income has declined secularly rather than risen. houses, consumer durable goods, and the like.

Our results have a bearing on another aspect of the so-called precautionary motive, namely, the view that the amount of cash balances held is highly sensitive to "the" or " $a$ " rate of interest, at least for some range of rates of interest. If this were so for rates of interest within the range observed during the period our data cover, it would imply that real cash balances and the ratio of income to money would be highly variable, both secularly and cyclically, since small movements in interest rates would be accompanied by large movements in desired cash balances. The highly stable secular behavior of velocity is evidence against this view. So is our inability to find any close connection between changes in velocity from cycle to cycle and any of a number of interest rates. So also is our finding that most of the cyclical movement in income velocity as ordinarily measured can be accounted for by the use of measured rather than permanent income in the numerator. The remaining movement in velocity, though characterized by a consistent cyclical pattern and though, on the basis of our tentative explorations, it may well be accounted for by movements in interest rates, is much too small to reflect any very sensitive adjustment of cash balances to interest rates.

Some of these comments about the implications of our results for the theory of money have their direct and obvious counterparts for the empirical study of business cycles. The most important additional implications are two that have to do with the interpretation of cyclical movements in velocity. The fact that velocity changes have been about as important as changes in the stock of money 
in accounting, in an arithmetic sense, for the movements in money income, together with the small amplitude of cyclical movements in the stock of money, has fostered the view that changes in the stock of money cannot be the prime mover, or even of major independent importance, in cyclical change. This view may of course be correct, but it needs re-examination in light of our finding that most of the velocity movement is, from one point of view, "spurious," as well as a possible consequence of this finding, discussed more fully below, that measured income may be highly sensitive to changes in the stock of money. The other important implication for the study of cycles is that the cyclical pattern of velocity changes that needs study and explanation is very different from what it has been supposed to be. Measured velocity has a cyclical pattern roughly synchronous with that in general business, tending to rise relative to its trend from reference trough to reference peak and to fall from reference peak to reference trough. But when this pattern is corrected for the deviation of measured income from permanent income, the residual movement is very different, and it is the residual movement that needs explanation.

The most interesting implication of our analysis for monetary policy is highly speculative and involves taking our findings more seriously in detail than I can fully justify. It may nonetheless be worth recording if only in the hope of stimulating further work. Suppose one accepts fully both the reasonably wellsupported finding that money holdings are adapted to permanent magnitudes and also the much more questionable and tentative suggestion that the economic actors derive their estimates of permanent magnitudes from prior measured magnitudes by implicitly constructing some kind of weighted average of them. It will then follow that, given a stable demand function for money, measured income will be highly sensitive in short periods to changes in the nominal stock of money-the short-run money multiplier will be large and decidedly higher than the long-run money multiplier. ${ }^{22}$ To illustrate with some figures based on our tentative results: In the long run, if we take real income as given, a $\$ 1$ increase in the stock of money would imply an annual level of money income higher than otherwise by $\$ 1$ times the velocity of circulation, or, at current levels of velocity, about $\$ 1.50$ higherthe long-run money multiplier equals the velocity of circulation. In the short run, however, an increase of $\$ 1.50$ in measured income would be inadequate, since that much of a rise in measured income would raise permanent money income by decidedly less than $\$ 1.50$ and hence desired cash balances by less than $\$ 1$. If we take a year as our unit and accept the numerical weights we have used in estimating permanent income from measured income, measured income would have to rise by roughly $\$ 4.50$ for estimated permanent income to rise by $\$ 1.50$, the rise required to raise desired cash balances by $\$ 1$ for given real income-the short-run money multiplier is thus triple the long-run multiplier.

The story does not, of course, end here. There would be carry-over effects into future years, as estimated permanent income continued to be revised in the light of measured income. These would make the initially assumed rise in money income not sustainable without further rises in the stock of money and hence would give rise to a cyclical reac-

\footnotetext{
${ }^{22}$ This point was first suggested to me by Gary S. Becker.
} 
tion in measured income. Further, the assumed change in money income would presumably be associated with changes in output and in prices that would affect the relation of desired cash balances to the change in measured money income. These further complications require much more study than I have given them. They do not, however, affect the main point-the sensitivity of measured income to changes in the stock of money that is implied by our results if they are accepted at face value.

It is interesting that the permanentincome hypothesis should have such contrasting implications for the sensitivity of the economy to changes in the stock of money and to changes in investment - the major other factor regarded as a prime mover in cyclical change. The permanent-income hypothesis implies that the economy is much less sensitive to changes in investment than it would be if consumption were adapted to measured rather than permanent income- - the short-run investment multiplier is decidedly smaller than the longrun multiplier. ${ }^{23}$ On the other hand, we p. 238. have just seen that the economy is much more sensitive to changes in the stock of money than it would be if money balances were adapted to measured rather than permanent income.

A corollary for policy is that the effects of monetary policy may be expected to operate rather more than would otherwise be supposed through the direct effects of changes in the stock of money on spending, and rather less through indirect effects on rates of interest, thence on investment, and thence on income. Another corollary is to emphasize the potency of relatively small changes in the stock of money-a potency, needless to say, for good or evil. Relatively small changes in the stock of money, properly timed and correct in magnitude, may be adequate to offset other changes making for instability. On the other hand, relatively small changes in the stock of money, random in timing and size, may equally be an important source of instability. If the reaction mechanism I have described is in any substantial measure valid, the system may not have a large tolerance for mistakes in monetary management. 